\title{
POLÍTICAS LINGUÍSTICAS E METODOLOGIA DE ENSINO- APRENDIZAGEM DE LÍNGUAS: ALGUMAS REFLEXÕES SOBRE A HISTÓRIA E A ATUALIDADE
}

Language policies and language teaching-learning methodologies: some reflections on their history and present situation

\section{Christian PUREN ${ }^{1}$}

Tradução de Valdilena RAMMÉ,Universidade Federal da Integração Latino-Americana

\section{APRESENTAÇÃO}

Christian Puren é um professor, formador e pesquisador francês em didática das línguas, especializado em francês e espanhol como línguas estrangeiras. Após uma longa carreira docente em universidades francesas e estrangeiras, ele recebeu em 2008 o título de Professor Emérito da Universidade de Saint-Étienne (França). Ele é, ainda, presidente de honra da APLV (Association française des Professeurs de Langues Vivantes) e do GERES (Groupe d'Etude et de Recherche en Espagnol de Spécialité), além de trabalhar ativamente em comitês científicos de diversas revistas francesas e estrangeiras dedicadas à didática de línguas-culturas.

Puren publicou, desde os anos 80, mais de 150 artigos sobre o tema da didática das línguas e é, ainda, autor de duas obras - Histoire des méthodologies de l'enseignement des langues (1988) e La didactique des langues à la croisée des méthodes. Essai sur l'éclectisme (1994) -, que podem ser baixadas gratuitamente de seu site pessoal (www.christianpuren.com), onde o leitor também encontra uma longa lista de artigos científicos, ensaios e manuais (a quase totalidade de sua produção) distribuídos livremente.

A concepção teórica que guia seus trabalhos centra-se no que o autor chama de “didática complexa das línguas-culturas", ideia esta exposta em um manifesto de 2003 intitulado "Pour une didactique comparée des langues-cultures", e igualmente disponível em seu site pessoal. Dentro desta perspectiva, ele tem abordando temas tão diversos como a análise de manuais, autonomia, literatura, competência cultural,

1 www.christianpuren.com (As notas de rodapé deste artigo são traduções das notas originais do autor. Quando não for o caso, indicaremos com a mensagem "NOTA DA TRADUTORA"). 


\section{DOSSIÊ ESPECIAL: DIDÁTICA SEM FRONTEIRAS (orgs.) \\ CHEREM, RAMMÉ, PEDRA \& OLMO \\ Revista X, vol.2, 2014}

documentos autênticos, pedagogia de projetos, entre outros. A partir de 2000, com a publicação do Quadro Comum Europeu de Referência, o autor tem se concentrado na questão da concepção e aplicação da perspectiva acional. ${ }^{2}$

Neste texto, Puren faz uma grande revisão crítica da história do ensino de línguas estrangeiras na França, entre elas o francês como língua estrangeira, discutindo a intersecção entre o projeto político europeu para as línguas e os projetos pedagógicos que, no que lhe dizem respeito, conversam com as pesquisas científicas e acadêmicas em didática de línguas. Nesta discussão, o autor debate igualmente a hierarquização desses projetos, ponderando sobre a influência do contexto no projeto político que, por sua vez, influencia o projeto pedagógico.

Valdilena Rammé

\section{INTRODUÇÃO}

No texto de orientação desta edição, os autores de Dialogue propuseram que seus diferentes colaboradores, cada um a partir de sua perspectiva e à sua maneira, "lançassem uma luz sobre a articulação entre os projetos educacionais, modalidades e práticas de ensino, e seu contexto ideológico e político". Parece-me que existe entre, de um lado, a educação (colocada como resultante do projeto), e de outro lado, o ideológico e o político (posto como resultante do contexto), uma hierarquização implícita bastante compreensível vinda de um movimento educacional como o GFEN ${ }^{3}$, orientado naturalmente para a promoção proativa de seus valores. Ao mesmo tempo, quando os mesmos redatores de Dialogue escrevem, no mesmo texto orientador ...:
$\mathrm{O}$ projeto do Liberalismo: fazer do saber uma mercadoria, preparar os indivíduos para se tornarem executores, instalar o cenário de um mundo de competição onde os prazeres são outorgados pelo dinheiro fácil, difundir na mídia imagens de uma subjetividade dita "moderna", fechada sobre ela mesma.

... o que eles denunciam é, bem ao contrário, um projeto ideológico que vai se chocar (e felizmente!) contra o que podemos chamar de um "contexto educativo",

\footnotetext{
2 Informações baseadas no texto fornecido pelo próprio autor e disponível em sua página pessoal http://www.christianpuren.com/mon-cv-abrégél

3 GFEN: Groupe Français d'Éducation Nouvelle (Grupo Francês de Nova Educação) (NOTA DA TRADUTORA)
} 


\section{DOSSIÊ ESPECIAL: DIDÁTICA SEM FRONTEIRAS (orgs.) \\ CHEREM, RAMMÉ, PEDRA \& OLMO \\ Revista X, vol.2, 2014}

constituído particularmente pelos valores humanistas oficialmente promovidos pela instituição, e majoritariamente compartilhados pelos educadores (apesar de nem sempre serem colocados em exercício nas práticas de todos): espírito crítico, sentido de colaboração, gosto pelo esforço, abertura aos outros e autoestima.

O fracasso dos laboratórios de línguas na França nos anos 1970 pode, assim, ser explicado historicamente pela conjunção de múltiplos fatores negativos: falta de formação dos professores, problemas de manutenção, medo das panes que deixam o professor desprovido e da falta de controle coletivo constante, problemas administrativos criados pela divisão necessária das turmas, e questionamento dos exercícios estruturais e do modelo cognitivo behaviorista sobre o qual eles se apoiavam.... $)^{4}$, mas, sem dúvida, também ocorre aqui o fato de que a organização do laboratório de línguas (alunos fisicamente separados em cabines para trabalhar individualmente) feria diretamente os valores "solidariedade coletiva" (dos alunos) e "justiça pela igualdade de tratamento" (dos professores), valores estes ligados, principalmente no espírito de muitos professores, me parece, ao funcionamento do grupo, o trabalho individual ficando reservado para as atividades fora do tempo de aula.

Esta interpretação é discutível, e outras interpretações são possíveis; mas eu considero que os didáticos colocam peso demais, em suas análises das práticas de sala de aula, sobre as representações dos atores, e não suficientemente sobre suas concepções, as quais sempre refletem em parte valores ${ }^{5}$. Qualquer que tenha sido a verdadeira razão, este exemplo do abandono dos laboratórios de línguas no final dos anos 70 me parece mostrar todo o interesse que haveria, na formação de professores, em se propor estudos de caso deste tipo, que permitem descobrir e confrontar os sistemas de interpretação individuais. Estes sistemas constituem, de fato, verdadeiras ideologias pessoais, muito negligenciadas, ao meu ver, em relação às grandes ideologias coletivas, mesmo que estas últimas estejam enfraquecidas e que, nas relações entre atores do ensino-aprendizagem, as lógicas interpessoais tenham um papel, pelo menos, tão importante quanto o das lógicas sociais.

4 Cf. a análise que eu faço do abandono generalizado destes laboratórios no meu artigo «Nouvelle perspective actionnelle et (nouvelles) technologies éducatives : quelles convergences... et quelles divergences ? », cap. 4, pp. 1011, http://www.christianpuren.com/mes-travaux-liste-et-liens/2009e/.

5 Sobre essa oposição conceitual, cf. minha análise dos "Constituintes semânticos do conceito de "concepção [da ação]" ("Composantes sémantiques du concept de "conception" [de l'action]"), http://www.christianpuren.com/bibliothèque-de-travail/045/, e no meu blog a rúbrica http://www.christianpuren.com/2011/05/04/les-représentations-unconcept-de-plus-en-plus-fumigène/. 


\section{DOSSIÊ ESPECIAL: DIDÁTICA SEM FRONTEIRAS (orgs.) \\ CHEREM, RAMMÉ, PEDRA \& OLMO \\ Revista X, vol.2, 2014}

Em outros momentos da história, encontramos claramente uma conjunção entre um projeto educativo e um projeto político que se produz, como no final do século XIX, quando os métodos ativos da nova pedagogia coincidem com a vontade do Estado francês, após a derrota para a Prússia em 1871 e em um contexto de rivalidade exacerbada com a Alemanha e de forte competição internacional, de dinamizar o país através da modernização de seu sistema educativo. Eu já tive a chance de citar essas palavras de Charles Schweitzer (professor de alemão, e avô de Jean-Paul Sartre) em um discurso de entrega de prêmios em 31 de julho de 1893: “As línguas vivas fazem parte, a partir de agora, de nossa defesa nacional!"; e aquelas de Louis Liard, Vice-reitor da Academia de Paris, em um discurso pronunciado na abertura do Conselho acadêmico em 26 de novembro de 1902:

Por todos os lados, correntes de ideias, correntes de ciência, correntes de riqueza; valorização da terra, das forças da natureza e das forças do homem. (...) É preciso agir, sob pena de definhar, é preciso enfrentar as correntes, sob pena de ser deixado às margens, como os destroços de um naufrágio. Também um ensino nacional que não fosse intrepidamente moderno na substância e no espírito, não seria simplesmente um anacronismo, ele se tornaria um risco nacional.

Ora, é precisamente nesta época que Gabriel Compayré opõe, assim, a pedagogia moderna à pedagogia tradicional: “A alma não é uma matéria interna que se deixa moldar à nossa vontade, que obedece passivamente a tudo que empreendemos sobre ela: longe disso, ela reage constantemente, ela combina sua própria ação àquela do mestre que a instrui" (COMPAYRÉ, 1880, p. 383), e que, aplicando este princípio ativo ao ensino-aprendizagem de línguas, Émile Bailly, professor de alemão, considera que “uma língua (...) se aprender vivendo esta língua!” (BAILLY, 1903, p.178).

Eu não sou um filósofo da educação, mas um didático de línguas-culturas, e vou, então, me limitar aqui, no que tange ao "projeto educativo", à forma que ele toma na minha disciplina, a saber, aquela das "metodologias constituídas". Trata-se de macro coerências centradas sobre os modos de ensino e que, a partir disso, colocam em coesão os outros elementos heterogêneos que constituem o "campo didático", isto é, as finalidades, objetivos e conteúdos, os modelos (cognitivos, pedagógicos, linguísticos, ...) e os ambientes de ensino-aprendizagem ${ }^{6}$. Essas metodologias se reconhecem historicamente ao passo em que elas geraram tanto materiais de ensino quanto práticas

6 Cf. "Le champ (de la perspective) didactique : illustration du fonctionnement par deux expériences mentales", http://www.christianpuren.com/bibliothèque-de-travail/044/. 


\section{DOSSIÊ ESPECIAL: DIDÁTICA SEM FRONTEIRAS (orgs.) \\ CHEREM, RAMMÉ, PEDRA \& OLMO \\ Revista X, vol.2, 2014}

de ensino e de avaliação relativamente parecidos e estáveis ao longo de um certo número de anos - de uma década, como a metodologia direta dos anos 1900, até meio século, como a metodologia ativa, metodologia oficial do ensino francês dos anos 1920 aos anos $1960^{7}$.

Nos limites do presente artigo, eu apresentarei, em uma primeira parte, para ilustrar o mecanismo histórico da evolução das metodologias, os exemplos das metodologias direta e ativa, que têm uma "história atrelada", porque elas compartilham o mesmo núcleo duro metodológico (voltarei a este conceito mais adiante). Em uma segunda parte, eu aplicarei os conceitos e conhecimentos extraídos desta forma na análise da situação atual, fortemente complexa: ela é, de fato, marcada simultaneamente pela persistência do modelo de avaliação certificativa terminal (as provas de língua no baccalauréat $\left.^{8}\right)^{9}$, por uma "abordagem por competências" que a instituição escolar impulsiona há alguns anos no ensino de línguas e de todas as disciplinas escolares, pela emergência de uma nova metodologia em via de constituição, a "perspectiva acional", e enfim, pela existência de uma nebulosa de "didáticas do plurilinguismo" a serviço de uma "educação plurilíngue e multicultural".

\section{O MECANISMO HISTÓRICO DA EVOLUÇÃO E DA ELABORAÇÃO DAS METODOLOGIAS}

A primeira grande ruptura metodológica que interveio na história do ensino de línguas é a passagem da metodologia tradicional à metodologia direta, ocorrida na virada dos séculos XIX e $\mathrm{XX}^{10}$. Uma ruptura seguramente radical, já que se passa simultaneamente:

1. de um modelo pedagógico da transmissão-recepção a um modelo oposto, o da pedagogia ativa;

\footnotetext{
7 Sobre a sucessão destas metodologias e suas diferentes características, cf. meu livro "Histoire des méthodologies de l'enseignement des langues" (Paris : Nathan-CLE international, 1988), com acesso livre em meu site pessoal: http://www.christianpuren.com/mes-travaux-liste-etliens/1988a/.

8 O baccaluréat é uma prova acadêmica que os estudantes franceses e internacionais devem fazer, ao final do liceu (ensino médio), para poder ingressar na educação superior. No Brasil, uma avaliação semelhante seria o ENEM. (NOTA DA TRADUTORA)

9 Em relação à totalidade da evolução histórica das diferentes configurações didáticas e de suas metodologias, desde o final do século XIX até nossos dias, eu refiro o leitor interessado, no meu site pessoal, a um quadro que esquematiza essa evolução e ao seu comentário: «Évolution historique des configurations didactiques (modèle) » : http://www.christianpuren.com/bibliothèque-detravail/029/.

10 Para mais detalhes, referir-se a meu artigo "31 mai 1902 genèse d'une révolution méthodologique": http://www.christianpuren.com/mes-travaux-liste-et-liens/1993b/.
} 


\section{DOSSIÊ ESPECIAL: DIDÁTICA SEM FRONTEIRAS (orgs.) \\ CHEREM, RAMMÉ, PEDRA \& OLMO \\ Revista X, vol.2, 2014}

2. de um paradigma cognitivo - o paradigma indireto, onde se concebe o falar uma língua estrangeira como uma tradução mental instantânea a partir de um pensar em língua materna - ao paradigma oposto - o paradigma direto, onde se concebe o falar uma língua estrangeira como um pensar e falar indissociáveis, baseado no modelo de aprendizagem de crianças em relação a sua língua materna;

3. de uma priorização da formação intelectual - pela ginástica mental forçada pela reflexão comparativa sobre as duas gramáticas, materna e estrangeira, assim como por exercícios de aplicação em língua estrangeira - a uma nova política linguística em que se dá prioridade ao "objetivo prático", o de um uso efetivo da língua, em especial oral;

4. de um reconhecimento, nos grandes textos da literatura clássica estrangeira, dos valores considerados como transculturais - as línguas vivas estão, assim como as línguas mortas, a serviço das "Humanidades clássicas" - a um ensino das especificidades da cultura estrangeira contemporânea a partir de documentos autênticos recentes (literários e outros) - as línguas vivas se colocaram, a partir de então, a serviço das "Humanidades modernas"11.

No centro da nova macro-coerência metodológica, que vai cumprir de maneira coerente todos os constituintes didáticos, vai se criar um novo "núcleo duro" que combina os métodos correspondentes às três primeiras reorientações acima, i.e.. os métodos ativo, direto e oral ${ }^{12}$ : em outras palavras, pede-se a partir de então que o professor privilegie em classe todas as atividades que levam o aluno mesmo (método ativo) a falar (método oral) imediatamente em língua estrangeira sobre documentos em língua estrangeira (método direto).

Nos anos 1900 - as grandes instruções diretas datam de 1901, 1902 e 1908 -, a metodologia direta vai se construir para o ensino no primeiro ciclo sobre a aplicação deste núcleo duro à situação de sala de aula (descrição e manipulação dos objetos que

\footnotetext{
11 Passa-se assim da prioridade sobre o constituinte "transcultural" da competência cultural (a capacidade de reconhecer o que Emile Durkheim chamava de "fundo comum de humanidade") a uma prioridade sobre o constituinte "metacultural" ("meta" no sentido do termo "metalinguístico", que compreende os conhecimentos sobre a língua). Sobre o conjunto dos constituintes da competência cultural sucessivamente privilegiado no ensino de línguas, refiro o leitor ao meu artigo "Modèle complexe de la compétence culturelle (composantes historiques trans-, méta-, inter-, pluri-, co-culturelles): exemples de validation et d'application actuelles", http://www.christianpuren.com/mes-travaux-liste-et-liens/2011j/.

12 Entendo "método" no sentido de "unidade mínima de coerência metodológica": todos os métodos criados e empregados no decorrer da história das metodologias do ensino de línguas se organizam em pares opostos: método direto/indireto, transmissivo/ativo, dedutivo/indutivo, onomasiológico/semasiológico, etc. Cf. meu "Tableau des oppositions méthodologiques fondamentales", http://www.christianpuren.com/bibliothèque-de-travail/008/.
} 


\section{DOSSIÊ ESPECIAL: DIDÁTICA SEM FRONTEIRAS (orgs.) \\ CHEREM, RAMMÉ, PEDRA \& OLMO \\ Revista X, vol.2, 2014}

ali se encontram, enunciação das ações que ali se pode realizar), e então, às imagens que representam outros objetos e outras situações (a casa paterna, o corpo humano, as roupas, as quatro estações, os trabalhos de campo, um terminal de transporte, uma festa na cidade, etc.), enfim, a pequenos textos fabricados também descrevendo aos alunos lugares, personagens, e/ou situações concretas familiares.

Essa ruptura radical da metodologia direta pode ser considerada também como fundamental, já que, para o essencial, a concepção do ensino escolar das línguas vivas repousa ainda em parte, um século mais tarde, neste começo de século XXI, sobre essa mesma organização: nós a encontramos, de fato, até os dias atuais, no modelo de avaliação certificativa do final do ensino secundário, aquele das provas escritas ou orais de língua no baccalauréat.

No meu "História das metodologias" de 1988, eu não tinha conseguido estabelecer uma hierarquização entre os diferentes elementos que estavam interpostos no momento da aparição e elaboração da metodologia direta: novos objetivos sociais (transmitindo novas necessidades sociais), contexto político e educativo, profissionalização do corpo de professores, modelo alemão ${ }^{13}$, "método natural" e seu paradigma direto, enfim pesquisas em fonética e em psicologia experimental, em pleno desenvolvimento na época. Acredito que cheguei a esta hierarquia desde então: o primeiro elemento (cronologicamente e hierarquicamente falando) é uma nova necessidade social de uso das línguas estrangeiras em uma situação social determinada, o novo objetivo social correspondente é retomado no nível político e, em seguida, institucional.

Eu propus há alguns anos, para dar conta do mecanismo de evolução didática em ensino-aprendizagem de línguas, o conceito de "configuração didática", definido como um conjunto coerente (seus constituintes, de fato, se "autoconfiguraram" uns em relação aos outros, e cada um em relação ao todo) de um objetivo social linguístico e de um objetivo cultural de referência, de um agir de uso e de um agir de aprendizagem de referência, enfim, de uma construção metodológica.

Usarei o exemplo da metodologia ativa, que surge nos anos 1920. Ela é, como as outras, produto terminal de uma certa configuração didática:

13 Distintas formas da metodologia direta já começavam a aparecer na Alemanha na metade do século XIX, e a pedagogia alemã representava então para muitos (em particular para os professores franceses de alemão, os mais numerosos na época) o modelo de inspiração. 


\section{DOSSIÊ ESPECIAL: DIDÁTICA SEM FRONTEIRAS (orgs.) \\ CHEREM, RAMMÉ, PEDRA \& OLMO \\ Revista X, vol.2, 2014}

- A construção desta configuração didática começa a partir da emergência de uma nova necessidade social, no caso, a de um conhecimento prático - i.e. permitindo um uso efetivo em compreensão do oral e da escrita, e em expressão oral e escrita - da língua e da cultura estrangeira contemporânea.

- Esta nova necessidade faz emergir um novo objetivo social do ensino de línguas que o poder político vai delegar à instituição escolar, a saber, a capacidade de manter, mais tarde, com a língua-cultura estrangeira um contato à distância a partir de sua casa, em sua sala: é a "situação social de referência" desta configuração, que não é diferente daquela da metodologia tradicional ${ }^{14}$ (ainda não se prepara para o encontro efetivo com estrangeiros no país estrangeiro, o que será a nova situação social de referência a partir dos anos 1960, aquela da metodologia audiovisual e da abordagem comunicativa).

- Esse objetivo vai ser correspondido por uma ação social (ou "de uso") de referência, ou seja, a leitura de documentos autênticos com a finalidade de mobilização e de extração de conhecimentos linguísticos e culturais.

- A ação escolar (ou “de aprendizagem”) de referência vai se auto-configurar em homologia máxima com esta ação social (ou "de uso") ${ }^{15}$. Isso vai levar à "explicação de textos" (principalmente literários), que será elaborada através do ensino no segundo ciclo aplicando-se o núcleo duro da metodologia direta ao trabalho coletivo em sala de aula sobre documentos "autênticos", isto é, considerados como representativos na língua e cultura estrangeiras. Trata-se, para os alunos, através principalmente de uma articulação entre compreensão escrita e expressão oral em sala, de buscar coletivamente os objetivos conjuntos de mobilização a respeito do documento dos conhecimentos linguísticos e culturais ${ }^{16}$. Esta elaboração da explicação de textos é feita ao longo dos anos 1900-1920 - a primeira grande instrução ativa dará de 1925, mas a reflexão sobre a "leitura direta" dos textos literários começa já no início da década de 1900, desde que os

14 A metodologia tinha proposto a formação de alunos para um uso social da língua estrangeira em imersão (" $\mathrm{O}$ conhecimento prático das línguas vivas tronou-se uma necessidade tanto para o comerciante e o homem industrial quanto para o sábio e o letrado". Circular relativa ao ensino de línguas de 15 de novembro de 1901), mas não tinha encontrado uma maneira de trabalhar tal propósito em classe. A abordagem comunicativa a inventará muito mais tarde, nos anos 1970, com os exercícios sistemáticos de simulação no fim da unidade didática.

15 Essa "lei de homologia máxima" é uma das raras leis transhistóricas que eu consegui encontrar: sempre se privilegiou em sala a tarefa mais parecida com a ação para a qual queria-se preparar os alunos. Por exemplo, dentro da abordagem comunicativa, fazíamos os aprendizes comunicarem entre si como se fossem estrangeiros na sociedade estrangeira (em simulação) para prepará-los à comunicação em língua estrangeira com estrangeiros.

16 Para uma análse detalhada desta macro-atividade de referência, e sua possível evolução, refiro o leitor a meu artigo "Explication de textes et perspective actionnelle: la littérature entre le dire scolaire et le faire social": http://www.christianpuren.com/mes-travaux-liste-et-liens/2006e/. 


\section{DOSSIÊ ESPECIAL: DIDÁTICA SEM FRONTEIRAS (orgs.) \\ CHEREM, RAMMÉ, PEDRA \& OLMO \\ Revista X, vol.2, 2014}

metodólogos se perguntam sobre a aplicação da metodologia direta no ensino conjunto da língua e da cultura estrangeiras no segundo ciclo ${ }^{17}$. Nas décadas seguintes, seguindo os progressos das técnicas de reprodução e da emergência de novas mídias, esta atividade de explicação de textos será adaptada aos outros tipos de documentos autênticos: visuais (quadros de pintores famosos, fotos ...), orais (gravações radiofônicas, músicas ...), scriptovisuais (HQs, publicidade ...), audiovisuais (extratos de filmes, emissões de TV ...).

- Enfim, é sobre este esqueleto articulado - constituído portanto do objetivo social e da situação social de referência, assim como da ação de uso e da ação de aprendizagem de referência - que a metodologia correspondente vai vir, para seguir a metáfora, "tomar corpo", emprestando para tal, de seu ambiente, os elementos necessários ao todo, a saber, em particular, nos anos 1920, na época da elaboração inicial desta metodologia ativa: as finalidades educativas (formações intelectual, ética e estética); o modelo pedagógico (frontal e diretivo, centrado sobre o ensino); o modelo cognitivo, muito eclético (considera-se que a aprendizagem é feita, ao mesmo tempo, por memorização, por imersão, por conceptualização-aplicação e por reações verbais às perguntas do professor); o modelo linguístico (gramatica morfossintática); o modelo fonético (articulatório); o modelo cultural (a cultural patrimonial, que dá, necessariamente, uma prioridade absoluta aos documentos literários, os únicos ao mesmo tempo linguísticos e representativos deste tipo de cultura); e enfim as características do meio escolar (ensino coletivo, extensivo, recortado em horas dispersas, acesso dos alunos aos únicos documentos do manual, etc.).

Pode-se ver que as atividades centrais da explicação de textos correspondem perfeitamente a competências que se quer, na época, desenvolver nos alunos: se elas parecem superficiais hoje, é simplesmente porque a situação social e o objetivo social de referência mudaram. A metodologia continua fazendo, todavia, parte da "situação metodológica atual", posto que a explicação de textos continua, até os dias de hoje, o modelo central da avaliação certificativa de conclusão do ensino escolar de línguas aquele das provas orais ou escritas do baccalauréat - com todos os efeitos

17 Eu reproduzi em meu site pessoal as primeiras proposições, a partir de 1902, do germanista Adrien Godart, já bastante concretas e cujas grandes diretrizes serão conservadas até a última grande instrução ativa, em 1950: http://www.christianpuren.com/bibliothèque-de-travail/042/. A instrução de 1908 é, deste ponto de vista, uma instrução pivô, porque ela leva em consideração a problemática do ensino contíguos de língua e de cultura estrangeiras no ensino médio. 


\section{DOSSIÊ ESPECIAL: DIDÁTICA SEM FRONTEIRAS (orgs.) \\ CHEREM, RAMMÉ, PEDRA \& OLMO \\ Revista X, vol.2, 2014}

modalizadores down-top que se pode imaginar sobre as práticas dos professores, sobre os manuais, assim como sobre as expectativas dos alunos, dos pais e dos estabelecimentos...

\section{A “SITUAÇÃO METODOLÓGICA” ATUAL}

\section{Introdução}

Uma das particularidades da disciplina "línguas vivas" em relação às outras disciplinas escolares é, certamente, a influência importante que as orientações políticas europeias têm sobre ela há várias décadas, concretamente aquelas do Grupo de Projeto "Línguas Vivas", do Conselho da Cooperação Cultural do Conselho da Europa de Strasbourg (doravante COE), atualmente renomeado "Divisão das políticas linguísticas" ${ }^{\prime 18}$, orientações geralmente retomadas pela Comissão Europeia de Bruxelas. É, de fato, este grupo que rejeitou, nos anos 1970, para as diferentes línguas europeias, o Nível Elementar (Threshold Level, Nivel Umbral, etc), documento que participou fortemente da concepção e difusão da abordagem comunicativa nos anos 1970-1990. Até a publicação, em 2001, por este mesmo COE, do Quadro Comum Europeu de Referência para as Línguas (doravante QCER) ${ }^{19}$.

A nova situação social de referência levada em conta pelos autores do QCER, são as sociedades plurilíngues e pluriculturais da Europa atual; e a nova finalidade social que eles propõem para o ensino de línguas, é a formação de um "ator social" em língua-cultura estrangeira. Esta finalidade gera dois objetivos sociais principais, correspondentes aos dois grandes cenários da formação de um cidadão neste tipo de sociedade, a saber (1) a capacidade de viver (conviver harmoniosamente), e (2) a capacidade de trabalhar (co-agir eficazmente) em permanência - no exterior ou em seu

18 Cf. sua página no site do COE : http://www.coe.int/t/dg4/linguistic/default_fr.asp.

19 Versão digital em formato pdf: http://www.coe.int/t/dg4/linguistic/Cadre1 FR.asp (acesso em 5 de janeiro de 2012). Versão impressa: Didier, 2001. 


\section{DOSSIÊ ESPECIAL: DIDÁTICA SEM FRONTEIRAS (orgs.) \\ CHEREM, RAMMÉ, PEDRA \& OLMO \\ Revista X, vol.2, 2014}

próprio país - com pessoas de línguas e de culturas completamente ou parcialmente diferentes.

Esses dois novos cenários de ensino-aprendizagem de línguas impulsionam simultaneamente duas novas configurações didáticas ${ }^{20}:$ (1) aquela que certos didáticos reagrupam sob a designação de "didáticas do plurilinguismo", e que o COE, há algumas décadas, pretende mobilizar a serviço do projeto único, que ele propõe a todos os países europeus, de “ educação plurilíngue e intercultural”; (2) e a da "perspectiva acional”. Ao que é preciso acrescentar - é, aliás, a parte mais importante do QCER em número de páginas, e o responsável pelo seu sucesso em toda a Europa -, (3) uma "abordagem por competências" da avaliação, baseando-se em seis níveis (A1, A2, B1, B2, C1, C2) com suas escalas e descritores correspondentes.

Eu retomarei, nesta ordem, esses três constituintes da atualidade em didática das línguas-culturas. Nos limites deste artigo, sua analise será, necessariamente, sucinta e esquemática, e é por isso que referirei, frequentemente, o leitor a outros textos publicados.

\section{O projeto político de "educação plurilíngue e intercultural"}

Uma das novidades que surgiram em 2001 dentro do QCER foi o destaque dado a uma "competência plurilíngue e multicultural" que a Divisão das Políticas Linguísticas do COE rebatizou, mais tarde, como "educação plurilíngue intercultural”, e à qual ele consagra desde então, todos os seus trabalhos, e sobre a qual são fundadas todas as suas proposições, de uma maneira, ao mesmo tempo, tão sistemática, exclusiva e repetitiva que um didático de francês língua estrangeira, Bruno Maurer, publicou recentemente uma obra intitulada Ensino de línguas e construção europeia. $O$ plurilinguismo, nova ideologia dominante. Encaminho os leitores a meu longo «Compte rendu de lecture... et de relectures personnelles», no qual acrescento minhas próprias análises críticas, relembrando diferentes artigos que dediquei ao tema desde a publicação do QCER $^{21}$. Essas três características de todas as ideologias - a recorrência sistemática, exclusiva e repetitiva às ideias que ali estão organizadas em sistema

20 Cf. meu quadro geral da evolução histórica das configurações didáticas. Referências na nota 4 acima.

21 Online: http://www.christianpuren.com/mes-travaux-liste-etliens/2012a/. Pode-se também, em relação às análises críticas do QCER, ler o artigo: "Le CECRL : compte rendu du débat critique dans l'espace germanophone" de Anne Friederike Delouis. 


\section{DOSSIÊ ESPECIAL: DIDÁTICA SEM FRONTEIRAS (orgs.) \\ CHEREM, RAMMÉ, PEDRA \& OLMO \\ Revista X, vol.2, 2014}

fechado - são visíveis e periódicas em todos documentos recentes desta Divisão de Políticas Linguísticas, como no Guia para a elaboração de políticas linguísticas na Europa de 2001, do qual voltarei a falar adiante. Este documento é apresentado da seguinte maneira no site oficial do CEO:

A finalidade deste Guia é propor um instrumento de análise que serve de documento de referência à elaboração ou à reorganização do ensino de língua nos Estados membros. Ele se propõe a satisfazer a necessidade de elaborar políticas linguísticas em favor do plurilinguismo e da diversificação, seguindo uma medida deliberada e constituída de uma soma de decisões conectadas umas às outras.

A frase seguinte me parece um modelo de retórica "eurocrática": "Este Guia não sugere nenhuma medida de política linguística educativa particular, mas ele tem a ambição de clarificar os contextos e as respostas possíveis em concordância com princípios compartilhados". A opinião do COE, de fato e figurativamente, é somente consultiva, mas a margem de manobra visada aqui pelos autores do Guia abarca somente as medidas a serem tomadas para executar uma orientação única ("a educação plurilíngue"), aplicando-se princípios que eles consideram, a priori, "compartilhados" por todos. Os valores são uma coisa - e é muito difícil não concordar sobre aquelas que defendem os autores deste documento -, mas as interpretações, utilizações e instrumentalizações que se pode fazer com eles, desde que os utilizemos como "princípios", quer dizer, guias para a ação, são outra, sobre a qual os cidadãos europeus - e em particular os partidos políticos, sindicatos, associações e outros movimentos pedagógicos -, devem, em nome destes mesmos valores, ser capazes de fazer valer suas posições, suas críticas e suas contraposições. Pessoalmente, considero a publicação deste Guia como um verdadeiro ato de violência ideológico, e é surpreendente que ele não tenha suscitado, até o momento, mais reações negativas e firmes oposições.

Este documento - e aqui apresento uma das outras críticas que venho formulando há anos contra as "orientações” do COE em relação às línguas -, se encontra muito claramente dentro de uma "lógica da especialidade" e sabemos que ela deriva de uma verdadeira ideologia antidemocrática. Permitam-me celebrar aqui, à minha maneira, os 10 anos de publicação do QCER, retomando o que escrevi no mesmo ano de 2001 na revista da $\mathrm{APLV}^{22}$, As Línguas Modernas:

22 APLV: Association des professeurs de langues vivantes (Associação dos professores de línguas vivas). (NOTA DA TRADUTORA) 


\section{DOSSIÊ ESPECIAL: DIDÁTICA SEM FRONTEIRAS (orgs.) \\ CHEREM, RAMMÉ, PEDRA \& OLMO \\ Revista X, vol.2, 2014}

Eu penso, particularmente, sobre o Quadro comum europeu de referência do Conselho da Europa, cujas "escalas de competência" são atualmente utilizadas, em muitos países europeus, para operações de harmonização forçada que são para a didática de línguas, mutatis mutandis, o que a exigência europeia de pasteurização leiteira foi para a produção francesa de queijos. Da mesma forma, [...] a elaboração e utilização atuais dos referenciais de competência do Quadro comum europeu devem, elas também, ser relacionadas com a lógica atual de estandardização dos produtos dentro do quadro do Mercado único. Pode-se aprovar uma tal lógica (é o caso de alguns de meus colegas europeus, portugueses por exemplo, que consideram que, em Portugal, os professores de línguas não recebem o suficiente de diretivas precisas e não são regularmente submetidos a avaliações), ou criticá-la (é o caso de certos formadores franceses, entre os quais eu me incluo, que consideramos, ao contrário, que já há em nosso país uma normatividade institucionalizada ${ }^{23}$ forte demais, herdade de sua cultura jacobina, e que não temos nada a ganhar substituindo um centralismo autoritário por outro); mas todos concordaremos que, espero, é pelo menos necessário estar consciente destas questões, e que elas merecem, pelo menos, ser discutidas. As tradições próprias do sistema escolar de cada país - e, no interior de cada uma delas, em relação ao ensino de cada língua - não devem certamente ser respeitadas tal qual, mas não vejo por que deveriam ter vantagem sobre aquelas as recomendações dos especialistas do Conselho da Europa autores deste Quadro comum europeu, e que neste momento não representam nem a si mesmos, posto que são anônimos. Os historiadores de nossa disciplina sem dúvida se espantarão, dentro de algumas décadas, sobre o fato que os didáticos europeus de línguas, apesar de especialistas em uma disciplina que coloca o desenvolvimento do sentido crítico entre seus objetivos explícitos, tenham sido, no questionamento da normalização tecnocrática, largamente ultrapassados pelos agricultores. (p. 13, as notas no rodapé são aquelas do texto original)

Esta ideologia da especialização, que é, desde o início, aplicada sobre as orientações de política linguística do COE, é combinada, no que diz respeito aos modos práticos do ensino, em conjunto com a técnica do benchmarking, muito conhecida da administração de empresas, mas que se torna um instrumento ideológico quando é utilizada em um domínio como o da política linguística. Aplicada ao ensino de línguas, essa técnica consiste em considerar que a inovação na área pode ser feita, principalmente, através da observação, da difusão e, em seguida, da generalização de "boas práticas" percebidas localmente. O leitor poderá se dirigir, para mais informações sobre esse ponto, a minha análise crítica intitulada "Quelques conclusions personnelles sur les Conclusions du Conseil sur l'indicateur européen des compétences linguistiques" de $2006^{24}$. Há, entre a lógica da especialização e a do benchmarking, uma combinação ideológica a serviço de uma divisão de tarefas entre os especialistas - que seriam os únicos habilitados a dizer a verdade oficial, porque ela seria "científica" - e a massa dos

23 Alguns falaram de "didática institucional", outros, como eu, de "metodologias oficiais", mas sob essas diferentes nomenclaturas, a realidade é exatamente a mesma.

24 Online : http://www.christianpuren.com/mes-travaux-liste-et-liens/2007a/. Trata-se de um documento do Conselho da União Europeia. 


\section{DOSSIÊ ESPECIAL: DIDÁTICA SEM FRONTEIRAS (orgs.) \\ CHEREM, RAMMÉ, PEDRA \& OLMO \\ Revista X, vol.2, 2014}

professores, considerados como executores das diretrizes e reprodutores dos modelos práticos.

\section{A nebulosa metodológica das "didáticas do plurilinguismo"}

Entre as orientações políticas e as metodologias empíricas "do campo", os “especialistas" autores do Guia para o desenvolvimento e aplicação dos currículos para uma educação plurilíngue e intercultural publicado pelo COE em 2010, fazem, então, o inventário, a título de representação metodológica dos "constituintes da planificação curricular" (p. 14), de todas as "medidas e atividades de aprendizagem que podem favorizar a aplicação de uma educação plurilíngue e intercultural” (pp. 105-109):

Dupla imersão (Dual Language Education) - Ensino bilíngue talvez trilíngue, CLIL / (EMI-LE, Language Across the curriculum) - Didática integrada das línguas (DIL) - Pedagogia integrada das línguas - Language awareness (UK) - Sensibilização às línguas (FR) - Sensibilização e abertura às línguas na escola (EOLE) (CH) - Intercompreensão - Pedagogia do encontro Mobilidade virtual - Prática intercultural - Currículo mínimo (uma semana) Utilização de suportes plurilíngues em cursos de outras matérias.

Anexo V, pp. 105-110.

(retomo textualmente os títulos da primeira coluna vertical deste quadro)

Vê-se que se trata de uma enumeração heteróclita de objetivos, de organizações curriculares, de disposições, de processos, assim como de medidas propriamente ditas que ninguém pode entender nem como "configuração didática", nem mesmo como "metodologia constituída". O único constituinte comum que todos esses elementos compartilham é que eles são obrigados a responder a uma mesma direção política de diversificação das línguas aprendidas. Eles estão, efetivamente, a serviço da "educação plurilíngue", mas não obrigatoriamente da "educação intercultural”, para a qual há, aliás, nesta lista, uma medida específica. Pode-se assim imaginar um ensino intensivo de uma língua em uma semana que visaria somente uma competência de comunicação linguística "de sobrevivência", ou ainda, o uso de suportes plurilíngues para um simples enriquecimento mais ou menos pontual de informações técnicas.

O ensino de línguas, abrindo-se a todas estas medidas e atividades múltiplas, pode, certamente, ganhar em leveza e adaptabilidade, mas por outro lado, ele perde em coerência: sem mencionar que a complexidade do ofício do professor de línguas explodiu na última década. Essa evolução seria positiva se o sistema de formação 


\section{DOSSIÊ ESPECIAL: DIDÁTICA SEM FRONTEIRAS (orgs.) \\ CHEREM, RAMMÉ, PEDRA \& OLMO \\ Revista X, vol.2, 2014}

profissional inicial e contínua a tivesse seguido, e se tivessem sido realizadas avaliações não só rigorosas como também regulares dos efeitos e resultados efetivos destas diferentes "medidas e atividades podendo favorizar a aplicação de uma educação plurilíngue e intercultural”, e de suas condições de eficácia. Ora, não é este o caso, e certos didáticos das línguas, entre os quais eu me coloco, começam a se inquietar seriamente e a tocar o alarme frente ao que eles consideram "tapar o sol com a peneira" de forma irresponsável em relação aos objetivos linguísticos que devem continuar sendo a base deste ensino, porque eles são os únicos a poder ser avaliados mais ou menos objetivamente (cf. também, em obra mencionada na sequência, ao fim do ponto 2.2 , a longa citação de Bruno Maurer).

\section{A perspectiva acional}

O impulso inicial da perspectiva acional surgiu em 2011 a partir do QCER, que propôs como novo objetivo/finalidade social de referencia para o ensino-aprendizagem de línguas-culturas a formação de um futuro "ator social", considerando, ao mesmo tempo, os alunos como atores sociais completos dentro do espaço e do tempo da sala de aula, e dentro de sua atividade coletiva de aprendizagem dentro de sua micro-sociedade sala. Ora, trata-se da finalidade e do princípio pedagógico que são a base mesmo da dita "pedagogia por projetos", de forma que há, atualmente, em didática de línguas e culturas, uma conjunção admirável - que não existia na configuração anterior, da abordagem comunicativa -, entre um projeto político, de um lado, e um projeto educativo que o GFEN (com seu Setor de Línguas), e os outros movimentos pedagógicos como o ICEM (Instituto Cooperativo da Escola Moderna-Pedagógica Freinet, com seu Grupo Línguas vivas) e o CRAP - Cadernos pedagógicos, somente podem, me parece, defender: que seja suficiente reproduzir aqui as duas citações atualmente publicadas no site do $\mathrm{GFEN}^{25}$ em evidência dentro de seu último, texto de orientação", de outro lado:

\footnotetext{
A Nova Educação prepara na criança, não somente o futuro cidadão capaz de preencher seus deveres em relação a seus próximos e a humanidade em seu todo, mas também o ser humano consciente de sua dignidade humana.

Princípio da Liga Internacional de Educação Nova, 1921 Contribuir conjuntamente a formar o Homem e o Cidadão, a iluminar a ação pelo pensamento, a animar o pensamento pela ação.
}

25 http://www.gfen.asso.fr/fr/texte_d_orientation_2010 Acesso em 29 de janeiro de 2012. 


\section{DOSSIÊ ESPECIAL: DIDÁTICA SEM FRONTEIRAS (orgs.) \\ CHEREM, RAMMÉ, PEDRA \& OLMO \\ Revista X, vol.2, 2014}

Henri Wallon

$\mathrm{Eu}$ somente posso, desta forma, encorajar os professores de línguas dos movimentos pedagógicos a aproveitar da admirável conjunção histórica atual, em didática das línguas e culturas, entre seu projeto educativo, por um lado, e por outro, o projeto político de formação de um ator social na base da "perspectiva acional", para não se contentar com a proposição dos planejamentos das metodologias existentes em função de seus valores e de seus princípios pedagógicos, mas para se investir fortemente no processo, ainda atual e em curso, de elaboração prática desta nova coerência metodológica $^{26}$.

Desde a publicação do QCER, a Divisão das Políticas Linguísticas do COE parece ter abandonado a perspectiva acional em favor de seu novo projeto de "educação plurilíngue e intercultural". A perspectiva acional seria a partir de então o objeto de reservas explícitas, se eu estou interpretando corretamente esta passagem de uma intervenção recente de um de seus autores, Jean-Claude Beacco:

Porque o ensino de línguas pode tender a ficar limitado a objetivos funcionais (comunicar para fazer) e a minimizar assim objetivos como "comunicar para aprender" ou "comunicar para compreender (o mundo)". (p. 1)

Sublinho: apreciaremos a prudência extrema e linguisticamente um pouco acrobática da primeira fórmula destacada, prudência perfeitamente compreensível da parte do autor: eu me pergunto somente de onde ele pôde tirar um conhecimento tão geral do que acontece nas práticas de ensino de todas as línguas, para todos os públicos, em todos os níveis, em todas as instituições e organismos em toda a Europa...

As instituições escolares não esperaram 2010 e os "especialistas" do COE, na França e em outros lugares da Europa, para preconizar no ensino de línguas o "aprender a aprender"; e a "compreensão do mundo" (pela descoberta de outras culturas) faz parte há muito tempo das finalidades do ensino escolar das línguas. Eu mesmo constatei, em minhas pesquisas sobre a história da didática das línguas na França, que, ao contrário do objetivo prático que foi sacrificado sobre o altar das finalidades culturais, o Ministério Francês da Educação queixa-se de forma constante, há décadas, que os alunos não são

26 É a este objetivo que consagrei uma boa parte das minhas pesquisas teóricas e práticas desses dez últimos anos. Pode-se ter acesso às publicações que eu consagrei ao assunto em meu site pessoal, na seção "Mes travaux: liste et liens" (http://www.christianpuren.com/mes-travaux-liste-et-liens/). O leitor pode se limitar, caso não seja professor de língua, aos títulos dos capítulos de meu artigo programático de 2009: "Variations sur le thème de l'agir social en didactique des langues-cultures étrangères”, que estão listados na página de downloads: http://www.christianpuren.com/mes-travaux-liste-et-liens/2009b/. 


\title{
DOSSIÊ ESPECIAL: DIDÁTICA SEM FRONTEIRAS (orgs.) \\ CHEREM, RAMMÉ, PEDRA \& OLMO \\ Revista X, vol.2, 2014
}

formados de maneira satisfatória para uma comunicação a serviço das atividades da vida cotidiana. Em minha resenha da obra de Bruno Maurer mencionada acima, com quem concordo completamente, eu já citei esta passagem:

\begin{abstract}
Perda de marcos operacionais (o que ensinar?), falta de precisão sobre os modos de ensino de línguas, caracterizam os efeitos destas reformas sobre os domínios que constituíam até então o núcleo das habilidades profissionais dos professores de línguas.

Contudo, nossa experiência de formador, e de formador de formadores, nos mostra no dia-a-dia [...] que os professores continuam a ser confrontados a perguntas certamente menos excitantes filosoficamente e aos jogos políticos menos elevados, mas que são o cotidiano das salas de aula: alunos franceses, por exemplo, que, depois de quatro anos de colégio, não conhecem os valores/sentidos dos tempos do passado em inglês, que não reconhecem a diferença entre os distintos determinantes desta língua ou que ainda sofrem para compreender algumas frases faladas por um nativo. Será possível argumentar que se estamos nesta situação, é porque os métodos atuais não dão os frutos almejados. Sem dúvida, mas não é certo que será uma nova estratégia para não encarar o problema - do ensino dominantemente gramatical àquele centrado sobre as competências de comunicação, e amanhã, do ensino dessas últimas a um conjunto de know-how ligados à alteridade que ajudará a resolvê-los.

Vamos deslocar os problemas, destacar as novas competências, e considerar que as competências linguísticas virão por excesso. Mas não há nada mais certo. (p.31)
\end{abstract}

\section{A abordagem por competências}

Sabe-se da importância que tomou oficialmente a abordagem por competências desde a publicação no B.O., em 2006, da Base comum de conhecimentos e de competências. A competência $\mathrm{n}^{\circ} 7$ desta base corresponde perfeitamente à atividade de projeto, como se pode ver na apresentação, que utiliza, além disso, este conceito de "projeto":

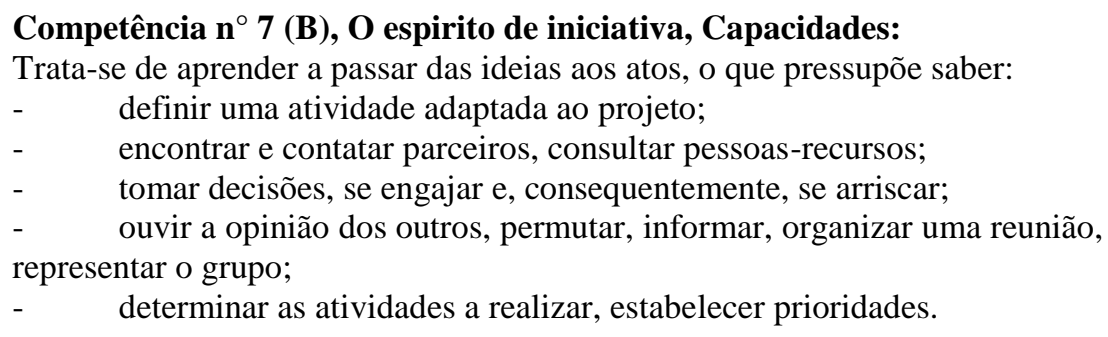

Pode-se, então, compreender que um movimento pedagógico como o CRAP possa ter apoiado uma tal abordagem para o conjunto de disciplinas escolares, com a publicação, desde 2007, de dois números de Cadernos pedagógicos (em 2009 e 2011), de dois números digitais extra (em 2007 e 2010), assim como uma obra na coleção "Marcos para agir" (ZAKHARTCHOUK \& HATEM, 2009). O que acontece é que, no 


\section{DOSSIÊ ESPECIAL: DIDÁTICA SEM FRONTEIRAS (orgs.) \\ CHEREM, RAMMÉ, PEDRA \& OLMO \\ Revista X, vol.2, 2014}

ensino de línguas, essa abordagem por competências - que não é nova: a abordagem comunicativa, nos anos 80, já se definia pelo seu objetivo de "competência de comunicação" desmembrada em diferentes constituintes -, é interpretada geralmente, pelo menos, como um trabalho específico sobre as atividades linguísticas (compreensões da escrita e do oral, expressões escrita e oral ${ }^{27}$ ), o que não traz nenhuma novidade; e, acima de tudo, esta abordagem por competências serve de ponto de apoio a certos (inclusive nos meios institucionais) para propor, por um lado, uma nova "pedagogia por objetivos", onde as práticas de ensino e de aprendizagem são conduzidas pelos descritores destas escalas de competências, e de outro, pelo desprezo à complexidade das funções da avaliação no ensino escolar ${ }^{28}$, uma concepção da avaliação reduzida a controles sucessivos de aquisição parcial destas competências. É nesta deriva frequente - que constitui uma clara regressão pedagógica - que se alude no texto de orientação do presente número de Dialogue "Educação e política", e do qual o primeiro parágrafo, depois da passagem citada na Introdução, continua e termina assim:

A obsessão pelo resultado a curto prazo afunda a escola na submissão. Esta escola multiplica as avaliações que fragilizam os sujeitos. Uma tal modernidade é companheira do se fechar sobre si mesmo e da degradação da autoestima.

\section{CONCLUSÃO}

A didática escolar das línguas vivas é, assim, confrontada desde o início do século XXI a uma enorme diversificação dos objetivos, público e ambientes de ensinoaprendizagem, assim como a uma dispersão muito forte dos constituintes didáticos (cf. nota 5 sobre o "campo didático") e dos constituintes metodológicos (abordagens, atividades, técnicas, procedimentos, métodos,... $)^{29}$, a serviço de projetos educativos e políticos diferentes, às vezes congruentes, por vezes opostos, e outras vezes, até mesmo contraditórios, se eu tomar como exemplo, nas publicações do COE da década que acaba de findar, a avaliação proposta aos professores dentro do QCER - linguística,

\footnotetext{
27 Tal é o caso nos "grupos de competências" instaurados pela instituição (cf. meu artigo crítico "À propos des "groupes de competences". E também é o caso da obra de J.-C. Beacco "L’approche par les compétences dans l'enseignement des langues" (Paris : Didier, 2007) (cf. a resenha crítica de Jean-Jacques RICHER em Les Langues modernes $\mathrm{n}^{\circ} 2 / 2008$, avril-mai-juin, pp. 86-88).

28 Cf. meu artigo analisando "La problématique de l'évaluation en didactique scolaire des langues".

29 Sobre esses diferentes conceitos, referir-se a meu quadro "Le champ sémantique de "méthode"". Online: http://www.christianpuren.com/bibliothèque-de-travail/004/.
} 


\title{
DOSSIÊ ESPECIAL: DIDÁTICA SEM FRONTEIRAS (orgs.) \\ CHEREM, RAMMÉ, PEDRA \& OLMO \\ Revista X, vol.2, 2014
}

analítica e objetivamente -, e nas finalidades culturais promovidas nos textos posteriores, que escapam a qualquer avaliação deste tipo.

A perspectiva acional em si, por mais interessante que seja, graças ao fato de estabelecer a concordância entre um projeto educativo humanista e um projeto político progressista, não tem vocação para organizar coerentemente todo esse conjunto de elementos. Poderemos ler, por exemplo, no site pessoal de André Giordan ${ }^{30}$, um artigo intitulado "O agir e o fazer", onde encontramos sua ideia central de uma diversificação indispensável dos modelos de ensino e de aprendizagem:

\begin{abstract}
Infelizmente, uma pedagogia da ação por si só continua estéril. A ação é, incontestavelmente, uma passagem obrigatória. Por outro lado, não se pode vislumbra-la, mesmo para os mais jovens, como uma resposta, mesmo que parcial, aos males atuais do ensino. Todas as avaliações mostram rapidamente seus limites. Ela só tem interesse quando relacionada com um projeto do aluno, a apropriação de um saber deve corresponder a uma necessidade. $\mathrm{O}$ mundo exterior não ensina diretamente ao indivíduo o que ele deve aprender. $\mathrm{O}$ indivíduo precisa criar sentido a partir do meio. A atividade tem sentido em função das condições nas quais se encontra o organismo e em função de sua historia. A ação pela ação ${ }^{31}$ pode, inclusive, se prejudicial, ela desencoraja os alunos tanto quanto pedagogias frontais.
\end{abstract}

Eis aqui, sobre a perspectiva acional que seria utilizada de maneira sistemática e exclusiva, uma crítica certamente mais fundamentada, mais consistente e mais respeitosa da inteligência dos leitores, do que o processo de intenção que vimos mais acima.

A administração do ensino escolar de línguas a partir das proposições do COE, que influencia fortemente e há uma década a política linguística francesa e as orientações didáticas e metodológicas do ensino de línguas neste país, deve ser objeto de um verdadeiro debate científico e de um verdadeiro debate democrático, dos quais, até agora, ela sempre escapou. Ora:

- As instruções oficiais do ensino de línguas na França são, desde a metade da década passada, "apoiadas” nos níveis e descritores de competência do QCER, com implicações muito concretas sobre os modos de ensino e de avaliação, os quais foram impostos de maneira autoritária e burocrática, sem que a formação, e mesmo a informação, dos professores fossem asseguradas corretamente, e sem que fosse

30 http://www.andregiordan.com/articles/apprendre/agirfaire.html (Acesso em 18 de janeiro de 2012).

31 Em uma entrevista recente, Philippe Meirieu relembra que ele vem denunciando desde os anos 1980, em pedagogia, o fenômeno de "totemização" (totémisation) da atividade dos alunos "empregada em seu sentido mais material": http://www.cafepedagogique.net/lexpresso/Pages/2012/02/06022012Accueil.aspx\#edito (Acesso em 6 de janeiro de 2012). Em sua obra de 1993, "Pour une pédagogie du projet", Isabelle Borsallo e Jean-Paul Ginestet falam, por sua vez, em relação a esse tipo de pedagogia, de um risco de "deriva produtiva” (p.12). O ensino de línguas não é obrigado a repetir os erros anteriormente cometidos pelos outros. 


\section{DOSSIÊ ESPECIAL: DIDÁTICA SEM FRONTEIRAS (orgs.) \\ CHEREM, RAMMÉ, PEDRA \& OLMO \\ Revista X, vol.2, 2014}

resolvida a contradição entre, de um lado, a nova lógica da avaliação - pelas competências e certificativa -, e de outro lado, as modalidades de provas de línguas no baccalauréat, assim como a avaliação contínua exigida dos professores ao longo do ano.

- Mesmo que sua elaboração não esteja terminada e que sua aplicação nos manuais e nas classes esteja apenas começando, a perspectiva acional já está abandonada, ou pelo menos seu "serviço de atendimento ao cliente" não está mais assegurado.

- Enfim, um novo projeto político diferente - "a educação plurilíngue e intercultural" - vem sendo proposto há alguns anos pela Divisão de Políticas Linguísticas do COE, sobre o qual podemos imaginar, levando em conta o que podemos constatar, que a instituição irá querer impô-lo quando chegar a sua hora, mas que ela o fará com o mesmo grau de improvisação e de insuficiência na sua subsequente observação e avaliação, mesmo que ele se estenda sobre o centro mesmo do ofício dos professores de línguas, e que ele implique, com suas múltiplas "didáticas do plurilinguismo", um rebentamento inédito dos objetivos, organizações e modos de ensino.

A vigilância das associações e movimentos pedagógicos, assim como sua reivindicação por um debate democrático, antes de qualquer importação precipitada de orientações didáticas fabricadas por "especialistas" em uma irresponsabilidade perfeita (eles podem estabelecer, a priori, restrições de aplicação in loco e não precisam se responsabilizar, a posteriori, pelas consequências práticas de suas recomendações). Essa vigilância e essa reivindicação são ainda mais necessárias, porque essas orientações didáticas levam necessariamente a orientações políticas e ideológicas, e porque elas podem abrir espaço para desorientações ou desvios.

A título ilustrativo, eu proporei algumas observações sobre algumas das "etapas de elaboração de um currículo" apresentadas no capítulo 2.1 .2 (pp. 28-29) do Guia para o desenvolvimento e aplicação de currículos para uma educação plurilíngue $e$ intercultural:

\begin{tabular}{|l|l|}
\hline Etapas & Observações \\
\hline$[\ldots]$ & \\
\hline - caracterização da situação sociolinguística de & Compreende-se que se busca a \\
referência e dos repertórios linguísticos & partir da realidade dos alunos \\
\hline
\end{tabular}


DOSSIÊ ESPECIAL: DIDÁTICA SEM FRONTEIRAS (orgs.)

CHEREM, RAMMÉ, PEDRA \& OLMO

Revista X, vol.2, 2014

\begin{tabular}{|c|c|}
\hline individuais dos aprendizes & (princípio pedagógico básico). \\
\hline Análise das necessidades linguísticas & $\begin{array}{l}\text { - Não se deve esquecer que se trata } \\
\text { também de oferecer a estes } \\
\text { aprendizes os meios para fugir de } \\
\text { seus determinismos sociais (e- } \\
\text { ducare = construir além). } \\
\text { - Também é preciso tomar cuidado } \\
\text { para que essas etapas não acabem } \\
\text { legitimando ciclos de seleção } \\
\text { precoce com base em uma seleção } \\
\text { social. }\end{array}$ \\
\hline$[\ldots]$ & \\
\hline $\begin{array}{l}\text { - elaboração dos documentos programáticos } \\
\text { levando-se em conta as restrições (carga horária } \\
\text { de ensino disponível, quantidade de alunos por } \\
\text { grupos, recursos técnicos tais como manuais, } \\
\text { material de ensino, espaços e locais), } \\
\text { especificando as metodologias de ensino, a } \\
\text { natureza das atividades de classe, os campos, } \\
\text { situações de comunicação, gêneros do discurso } \\
\text { considerados dentro do ensino, as formas das } \\
\text { sequências didáticas ou dos módulos de ensino, } \\
\text { assim como as indicações sobre a divisão linear } \\
\text { dos conteúdos de ensino. (grifo do autor) }\end{array}$ & $\begin{array}{l}\text { Da forma como ela é apresentada } \\
\text { aqui, esta etapa coloca em causa o } \\
\text { princípio da liberdade pedagógica } \\
\text { dos professores, liberdade } \\
\text { necessária tanto de um ponto de } \\
\text { vista de coerência ideológica (um } \\
\text { professor executor não é capaz de } \\
\text { formar futuros cidadãos } \\
\text { responsáveis), como da eficiência } \\
\text { prática (a complexidade somente } \\
\text { pode ser gerada em tempo real e em } \\
\text { sala). }\end{array}$ \\
\hline
\end{tabular}

Estas poucas observações, assim como o meu texto como um todo, pretendem ser uma contribuição pessoal a um debate democrático, totalmente inexistente nestas últimas décadas, sobre as orientações politicas e didáticas no ensino escolar francês de línguas. A análise histórica demonstra que são os usos sociais, aos quais se quer preparar os alunos, que determinam fundamentalmente todas as configurações didáticas. Não chegaremos mais a uma configuração única, como existia no passado, porque os 


\section{DOSSIÊ ESPECIAL: DIDÁTICA SEM FRONTEIRAS (orgs.) \\ CHEREM, RAMMÉ, PEDRA \& OLMO \\ Revista X, vol.2, 2014}

usos sociais estão profundamente diferentes, e porque pensamos ser legítimo preparar os aprendizes para eles. Porém, levando-se em conta a questionável eficiência do sistema escolar francês em selecionar os alunos a partir de critérios criados desde a análise de critérios sociais, pode-se temer que as diferenças curriculares no ensino de línguas acabarão por reproduzir e reforçar as diferenças sociais. É esse risco maior, do qual o ensino não conseguiu se esquivar nos anos passados (cf. a escolha de línguas pouco ensinadas ou de línguas reforçadas por constituir "campos de excelência"), que exige de todos os coletivos de professores de língua na França, nos próximos anos, a mais completa vigilância.

\section{REFERÊNCIAS BIBLIOGRÁFICAS}

BAILLY, É. L'enseignement de l'allemand dans l'école allemande et la méthode intuitive (I). In: Les Langues Modernes, $n^{\circ}$ 6, déc. 1903, pp. 168-179. Paris: APLV, 1903.

BEACCO, J-C. Les dimensions culturelles et interculturelles des enseignements de langues: état des pratiques et perspectives. Texto apresentado no Seminário sobre Convergences curriculaires pour une éducation plurilingue et interculturelle. Strasbourg, 29-30 de novembro de 2011. Disponível em : www.coe.int/lang/fr.

BORDALLO, I. \& GINESTET, J-P. Pour une pédagogie du projet. Paris: HachetteÉducation, 1993.

COMPAYRÉ, G. Histoire critique des doctrines de l'éducation en France depuis le XVIe siècle. Paris : Hachette Éducation, 2e éd., T. 1, 1880.

CONSEIL DE L'EUROPE. De la diversité linguistique à l'éducation plurilingue: Guide pour l'élaboration des politiques linguistiques éducatives en Europe. Strasbourg: Conseil de l'Europe, Division des Politiques linguistiques, 2007. Disponível em: http://www.coe.int/t/dg4/linguistic/Guide niveau2_FR.asp. Acesso em 02/02/2012. CONSEIL DE L'EUROPE. Guide pour le développement et la mise en oeuvre de curriculums pour une éducation plurilingue et interculturelle. Strasbourg: Conseil de l'Europe, Division des Politiques linguistiques: septembre 2010. Disponível em: http://www.coe.int/T/DG4/Linguistic/Source/Source2010_ForumGeneva/GuideEPI201 0_FR.pdf. Acesso em: 31 de janeiro de 2012.

CONSEIL DE L'EUROPE, CONSEIL DE LA COOPÉRATION CULTURELLE \& COMITÉ DE L'ÉDUCATION. Les langues vivantes: apprendre, enseigner, évaluer. Un Cadre européen commun de référence. Strasbourg, 1998.

FRIEDERIKE DELOUIS, A. Le Cadre européen: où en sommes nous? In: Les Langues modernes $n^{\circ}$ 2/2008, avril-mai-juin, pp. 19-31. Paris: APLV, 2008.

MAURER, B. Ensino de línguas e construção europeia. O plurilinguismo, nova ideologia dominante. Paris: Éditions des archives contemporaines, 2011.

MINISTĖRE DE L'ÉDUCATION NATIONALE, DE L'ENSEIGNEMENT SUPÉRIEUR ET DE LA RECHERCHE. Base comum de conhecimentos e de competências. In: B.O. $\mathbf{n}^{\circ}$ 29, de 20 de julho de 2006. Disponível em: 


\section{DOSSIÊ ESPECIAL: DIDÁTICA SEM FRONTEIRAS (orgs.)}

CHEREM, RAMMÉ, PEDRA \& OLMO

Revista X, vol.2, 2014

http://www.education.gouv.fr/bo/2006/29/MENE0601554D.htm Acesso em 4 de janeiro de 2012.

PUREN, C. 31 mai 1902 genèse d'une révolution méthodologique. In: Études de Linguistique Appliquée, n ${ }^{\circ}$ 90, avril-juin, pp. 51-60. Paris : Klincksieck, 1993.

PUREN, C. La problématique de l'évaluation en didactique scolaire des langues. In: Les Langues modernes 2/2001: Évaluation et certification en langues. Paris: APLV, 2001. Disponível em : http://www.christianpuren.com/mes-travaux-liste-et-liens/2001e/. PUREN, C. La problématique de l'évaluation en didactique scolaire des langues. In: Les Langues modernes $n^{\circ}$ 2/2001, avr.-mai-juin. Paris: APLV, 2001. Disponível em: http://www.christianpuren.com/mes-travaux-liste-et-liens/2001e/.

PUREN, C. À propos des "groupes de compétences". In : ABDELGABER, S. \& MEDIONI M-A. (coord.). Enseigner les langues vivantes avec le Cadre européen. Hors-série numérique $\mathrm{n}^{\circ}$ 18, pp. 271-281. Paris: CRAP-Cahiers pédagogiques, 2010. Disponível em : http://www.christianpuren.com/mes-travaux-liste-et-liens/2010h/.

RICHIER, J-J. Resenha crítica de BEACCO, J-C. L'approche par les compétences dans l'enseignement des langues (Paris: Didier, 2007). In: Les Langues modernes $n^{\circ} 2 / 2008$, avril-mai-juin, pp. 86-88. Paris: APLV, 2008. 